\title{
Modeling and Parameter Optimization of Flexible NC Polishing Vibration of Abrasive Cloth Wheel Based on Sensitivity Analysis
}

\author{
Xiaojun Lin (D), Rui Yang ${ }^{(D,}$, Xiaopeng Xin, Zhaozhao Lei, and Luzhou Sun \\ School of Mechanical Engineering, Northwestern Polytechnical University, Xi'an, Shaanxi 710072, China \\ Correspondence should be addressed to Xiaojun Lin; linxj@nwpu.edu.cn
}

Received 2 February 2020; Revised 2 April 2020; Accepted 11 April 2020; Published 22 May 2020

Academic Editor: Łukasz Jankowski

Copyright (c) 2020 Xiaojun Lin et al. This is an open access article distributed under the Creative Commons Attribution License, which permits unrestricted use, distribution, and reproduction in any medium, provided the original work is properly cited.

\begin{abstract}
The blisk is a typical cantilever beam structure, which is prone to vibration during the polishing process. This vibration will cause the polishing tool to wear seriously and reduce the surface quality of the blade.In order to control the vibration of polishing process, a method of predicting the RMS (root mean square) value of polishing vibration signal was proposed. Firstly, an empirical model of process parameters for polishing vibration was established by an orthogonal experiment. Then, based on the response surface and sensitivity analysis method, the stability range of the process parameters and the influence on the polishing vibration are obtained. Finally, through the polishing experiment, it is determined that the stable range of each process parameter is reliable. There is no significant vibration during the polishing process. By analyzing the surface texture and surface topography of the blade, the surface quality of the blade meets the requirements. The results showed that the optimal stability ranges of significant parameters through sensitivity analysis are compression depth within [0.6 mm, $0.9 \mathrm{~mm}]$, spindle speed within [6000 r/min, $7500 \mathrm{r} /$ $\mathrm{min}]$, feed rate within $[0.4 \mathrm{~mm} / \mathrm{min}, 0.6 \mathrm{~mm} / \mathrm{min}]$, and granularity within [400\#, 600\#]. This study provides a basis for the theoretical research of polishing vibration in the flexible polishing process and the relationship between process parameters and polishing vibration.
\end{abstract}

\section{Introduction}

The blisk is the core component of an aircraft engine, and the service life of an aeroengine depends in no small extent on its quality $[1,2]$. After milling, there are still visible cutting marks on the blade surface, and its surface quality cannot meet the technological requirements [1]. For this reason, polishing is urgent to such kind of components and parts [2]. In China, the polishing of the blisk still relies on manual polishing. Because manual polishing has the disadvantages of large workload, difficult surface quality control, and low efficiency, it is necessary to study the automatic polishing.

In recent years, according to the structure and characteristics of the blisk, a large number of scholars have studied the automatic polishing. Axinte et al. $[3,4]$ researched the abrasive belt grinding process of Ti-6Al-4V alloy and established that it is feasible to use the abrasive belt as the final processing process of the engine components. Jourani et al. [5] studied the effect of abrasive belt grinding on surface quality, established a contact model between abrasive belt and workpiece, and analyzed the wear mechanism. Bigerelle et al. $[6,7]$ found a wear mechanism analysis model for abrasive belt grinding. Huang et al. [8] designed a new method of surface pretreatment of magnesium alloy based on belt grinding technology, which provides a new process for surface processing of magnesium alloy tubes. Tian et al. [9] established a robot polishing platform intending to improve quality and reduce cost. Pilny and Bissacco [10] developed a robot-assisted polishing system which installed an acoustic emission sensor and a force monitoring sensor on the polishing arm to realize the monitoring strategy of the process and polished surface features. The surface roughness of the free-form surface workpiece can be less than $10 \mathrm{~nm}$. Sun et al. [11] used robotic belts to polish complex profiles of metal parts. Mirian et al. [12, 13] polished the inner and outer surfaces of cylindrical parts on a 2-axis CNC machine. Dunn and Walker [14] proposed a random tool polishing path and numerical control subaperture polishing 
technology based on CNC machine tools. Zhang et al. [15] designed a six-axis CNC abrasive belt grinding equipment and studied the isoparametric path planning and equal spacing path planning algorithm on the free-form surface.

In the process of polishing the blisk, the polishing vibration will be produced due to the unsuitable process parameters. Larger polishing vibration will cause flutter phenomenon, and scaly ripple will appear on the blade surface, as shown in Figure 1. The vibration ripple on the surface of the blade increases the subsequent polishing allowance, and the polishing force increases accordingly. The change of the polishing force causes the vibration ripple to increase, and the surface roughness of the blade increased. To prevent large vibration during polishing and improve the stability of the polishing process and the surface quality of blades, it is necessary to study the vibration during the polishing process.

At present, the polishing vibration of flexible polishing technology of abrasive cloth wheel has not been studied. How to choose the appropriate process parameters to reduce the vibration during the polishing and improve the stability of the polishing process is a critical issue. Therefore, taking the abrasive cloth wheel polishing as the research object, the empirical model of polishing vibration was established by regression analysis of polishing experimental data, and the sensitivity analysis of the model was carried out, and the stability range of the process parameters was obtained. The experimental results show that the empirical model of polishing vibration can effectively predict the RSM value of polishing vibration signal, and within the stable range polishing can improve the stability of the polishing process and the surface quality of the blade.

\section{Experimental Methods and Materials}

2.1. Experimental Equipment and Materials. Polishing experiments were conducted on the YPGZ-1000 5-axis 5-linkage CNC abrasive cloth wheel polishing machine tool [16], which was researched and developed by our research group; the machine mechanism and motion axis are shown in Figure 2.

In this paper, the abrasive cloth wheel is used as the polishing tool in the polishing process of the blisk. Its structure is shown in Figure 3.

A sensor, Dytran3225M23, whose sensitivity is $49.7 \mathrm{mv} /$ $\mathrm{g}$, is chosen for measuring polished vibration signals.

The test piece is TC4 blade, which had a surface roughness of Ra $1.2 \mu \mathrm{m}$ to $1.4 \mu \mathrm{m}$ and surface microhardness of $300 \mathrm{HV}$ to $310 \mathrm{HV}$, as shown in Figure 4. Its composition and mechanical properties are shown in Tables 1 and 2.

2.2. Acquisition of Polishing Vibration Signal. In this paper, the RMS value of the vibration signal of the workpiece during the polishing process is used to characterize the vibration intensity [17]. The calculation formula is expressed as follows:

$$
\psi(x)=\sqrt{\frac{1}{N} \sum_{i=1}^{N} x_{i}^{2}}
$$

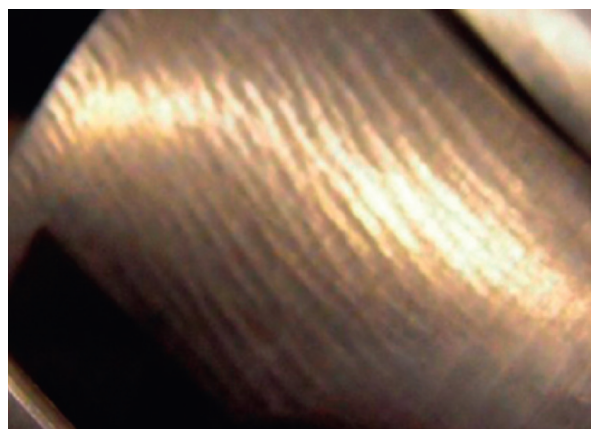

FIGURE 1: Surface ripple of the blade caused by polishing vibration.

where $\psi(x)$ is the RMS of the workpiece vibration signal. In this paper, $x_{i}$ is the discrete value of vibration signal of one polishing measured line and $N$ is the point number of one polishing measured line.

The acquisition of the polishing vibration signal is completed through the PC-based online detection system. The process of the acquisition of the signal is shown in Figure 5.

2.3. Experimental Program. The purpose of the polishing experiment is to establish a model of the polishing vibration and determine the relationship between the RMS value of the polishing vibration and various process parameters according to the model.

The main parameters affecting polishing vibration are spindle speed, feed rate, compression depth, and granularity $[18,19]$. When the spindle speed is higher than $7500 \mathrm{r} / \mathrm{min}$, the centrifugal force is increased. Due to the cylindricity error and dimensional error of the abrasive cloth wheel, the abrasive cloth wheel at high spindle speed is unbalanced, which may result in the unstable polishing process. When the spindle speed is less than $4500 \mathrm{r} / \mathrm{min}$, the number of abrasive grains involved in polishing per unit area is reduced, and the polishing efficiency is remarkably lowered. Therefore, the variation range of the spindle speed of the abrasive cloth wheel in this test is from $4500 \mathrm{r} / \mathrm{min}$ to $7500 \mathrm{r} /$ min. According to relevant literature $[18,19]$, the feed rate ranges from $0.2 \mathrm{~mm} / \mathrm{min}$ to $0.6 \mathrm{~mm} / \mathrm{min}$, and the compression depth ranges from $0.3 \mathrm{~mm}$ to $0.9 \mathrm{~mm}$. The commonly used abrasive cloth wheel granularity of 240\#, 400\#, and 600\# was selected as the three levels of this experiment. The test parameters of the polishing process are shown in Table 3. Four-factor and three-level orthogonal experiments are shown in Table 4.

2.4. Experiment Process. The experimental process is as follows. Firstly, the acceleration sensor is installed on the pressure surface of the blade to detect the response signal of system vibration. Secondly, the polishing experiments were carried out according to the order of the orthogonal test scheme by changing the corresponding technological parameters. Thirdly, the vibration signal is acquired by the DEWESOFT acceleration sensor, and the spectral characteristics are obtained by FFT transformation. The vibration 

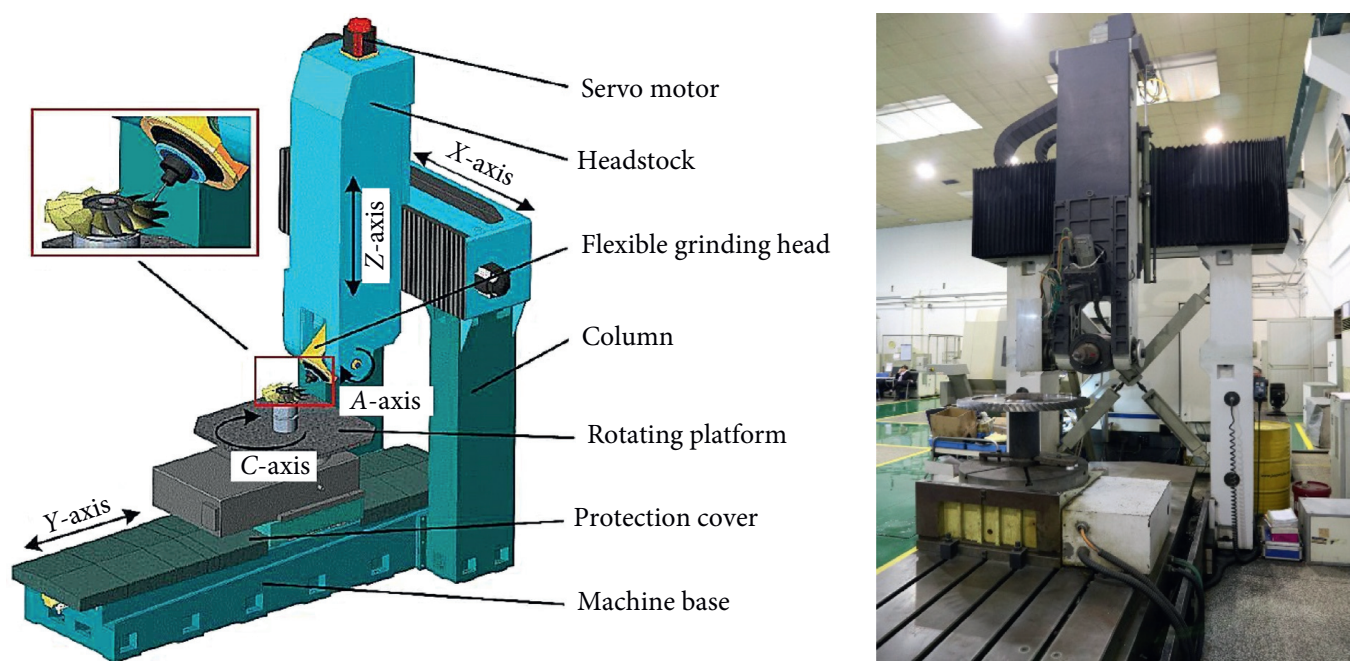

FIgure 2: Polishing machine structure.

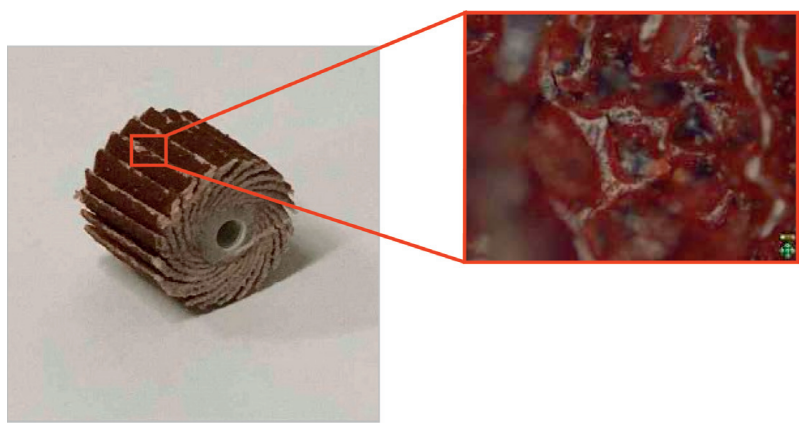

FIgURE 3: Abrasive cloth wheel.

intensity (polishing vibration RMS) was calculated using the MATLAB platform. The polishing test site is shown in Figure 6.

\section{Results and Discussion}

3.1. Establishment of Polishing Vibration Model. The empirical model of polishing vibration RMS can be expressed as an exponential or multivariate linear model, and its expression is as follows:

$$
\begin{aligned}
& \psi_{1}(x)=f\left(n, a_{p}, v_{f}, p\right)=c_{0} n^{c_{1}} a_{p}^{c_{2}} v_{f}^{c_{3}} p^{c_{4}} \\
& \psi_{2}(x)=f\left(n, a_{p}, v_{f}, p\right)=k_{0}+k_{1} n+k_{2} a_{p}+k_{3} v_{f}+k_{4} p
\end{aligned}
$$

Through regression analysis of equation (3), the final model expression is as follows:

$$
\psi_{2}(x)=0.217+0.000083 n+1.096 a_{p}+0.075 v_{f}-0.000574 p .
$$

Take the logarithm of both sides of formula (2) as shown in formula (3):

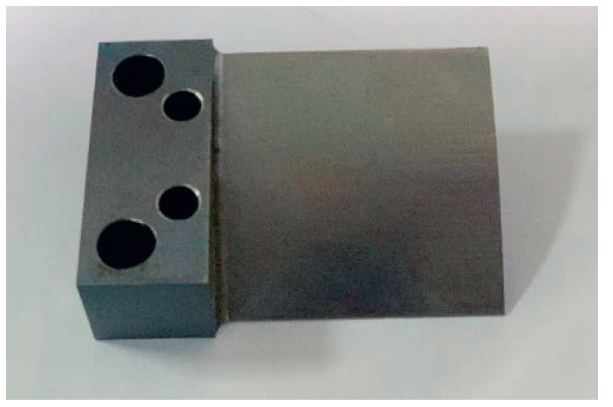

FIgURE 4: TC4 blade test piece.

$\ln \psi_{1}(x)=\ln c_{0}+c_{1} \ln n+c_{2} \ln a_{p}+c_{3} \ln v_{f}+c_{4} \ln p$.

According to the results of orthogonal test and linear regression analysis, the linear regression coefficient is shown in Table 5.

Finally, the RMS value model of polishing vibration signal is obtained as follows:

$$
\psi_{1}(x)=f\left(n, a_{p}, v_{f}, p\right)=10^{-0.92} n^{0.408} a_{p}^{0.467} v_{f}^{0.043} p^{-0.166},
$$

where $\psi(x)$ is the vibration RMS value, $n$ is spindle speed, $a_{p}$ is compression depth, $v_{f}$ is feed rate, and $p$ is granularity.

The variance analysis of equation (4) shows that $F=9.53$, and $F$ value is small, which means the equation is not significant and the fitting degree is not good, so the linear expression is not used as the empirical model of polishing vibration. The results of variance analysis of formula (6) are shown in Table 6. SS is the square of deviation, and MS is the mean square of variance. Taking the significance level $a=0.01, F=110.97>F_{0.01}(4,4)=15.98$. It shows that the model is significant and the fitting degree is good, so the exponential model is used as the empirical model of RMS value of polishing vibration. As shown in Figure 7 , in the 
TABLe 1: TC4 titanium alloy chemical composition.

\begin{tabular}{|c|c|c|c|c|c|c|c|c|c|c|c|}
\hline \multirow{4}{*}{ Mark } & \multirow{4}{*}{ Chemical composition } & \multicolumn{10}{|c|}{ Chemical constituents (mass fraction)\% } \\
\hline & & \multicolumn{3}{|c|}{ Main ingredient } & \multicolumn{7}{|c|}{ Impurity (not more than) } \\
\hline & & \multirow{2}{*}{$\mathrm{Ti}$} & \multirow{2}{*}{$\mathrm{Al}$} & \multirow{2}{*}{$\mathrm{V}$} & \multirow{2}{*}{$\mathrm{Fe}$} & \multirow{2}{*}{$\mathrm{C}$} & \multirow{2}{*}{$\mathrm{N}$} & \multirow{2}{*}{$\mathrm{H}$} & \multirow{2}{*}{$\mathrm{O}$} & \multicolumn{2}{|c|}{ Other elements } \\
\hline & & & & & & & & & & Single & Total \\
\hline TC4 & Ti-6Al-4V & Allowance & $5.5-6.8$ & $3.5-4.5$ & 0.30 & 0.10 & 0.05 & 0.015 & 0.20 & 0.10 & 0.40 \\
\hline
\end{tabular}

TABLE 2: TC4 titanium alloy mechanical properties.

\begin{tabular}{ccccccc}
\hline Mark & $\begin{array}{c}\text { Hardness } \\
(\mathrm{HRC})\end{array}$ & $\begin{array}{c}\text { Elastic modulus } E \\
\left(\times 10^{6} \mathrm{MPa}\right)\end{array}$ & $\begin{array}{c}\text { Yield limit } \sigma b \\
(\mathrm{MPa})\end{array}$ & $\begin{array}{c}\text { Elongation } \delta \\
(\%)\end{array}$ & $\begin{array}{c}\text { Impact toughness } \\
\mathrm{a}_{k} \\
\left(\mathrm{~J} / \mathrm{cm}^{2}\right)\end{array}$ & $\begin{array}{c}\text { Thermal conductivity } \\
\lambda \\
\left(\mathrm{J} / \mathrm{cm}^{2} \cdot \mathrm{s}^{\circ} \mathrm{C}\right)\end{array}$ \\
\hline TC4 & 30 & 0.113 & 932 & 10 & 39.24 & 0.068 \\
\hline
\end{tabular}

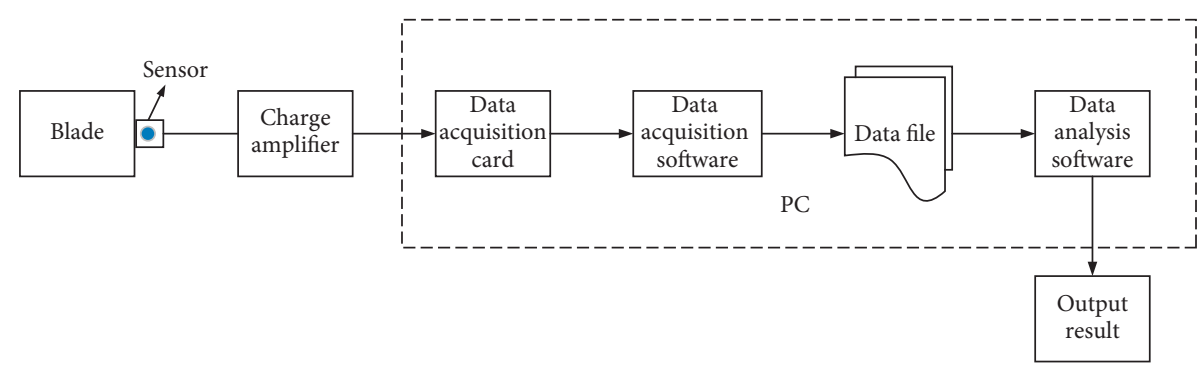

Figure 5: Signal acquisition process.

TABLe 3: Test parameters.

\begin{tabular}{lcccc}
\hline Number & Spindle speed $n\left(\mathrm{r} \cdot \mathrm{min}^{-1}\right)$ & Compression depth $a_{p}(\mathrm{~mm})$ & Feed rate $v_{f}\left(\mathrm{~m} \cdot \mathrm{min}^{-1}\right)$ & Granularity $P$ \\
\hline 1 & 4500 & 0.3 & 0.2 & 0.4 \\
2 & 6000 & 0.6 & 0.6 & 400 \\
3 & 7500 & 0.9 & 600 \\
\hline
\end{tabular}

TAвLE 4: Four factors and three levels of orthogonal experimental design and results.

\begin{tabular}{lccccc}
\hline Number & Spindle speed $n\left(\mathrm{r} \cdot \mathrm{min}^{-1}\right)$ & Compression depth $a_{p}(\mathrm{~mm})$ & Feed rate $v_{f}\left(\mathrm{~m} \cdot \mathrm{min}^{-1}\right)$ & Granularity $P$ & RMS value $\psi(x)\left(\mathrm{m} \cdot \mathrm{s}^{-2}\right)$ \\
\hline 1 & 4500 & 0.3 & 0.2 & 240 & 0.847 \\
2 & 4500 & 0.6 & 0.4 & 400 & 0.908 \\
3 & 4500 & 0.9 & 0.6 & 600 & 1.330 \\
4 & 6000 & 0.3 & 0.4 & 240 & 0.798 \\
5 & 6000 & 0.6 & 0.6 & 400 & 1.175 \\
6 & 6000 & 0.9 & 0.2 & 400 & 1.612 \\
7 & 7500 & 0.3 & 0.6 & 600 & 1.068 \\
8 & 7500 & 0.6 & 0.4 & 240 & 1.024 \\
9 & 7500 & 0.9 & & & 1.743 \\
\hline
\end{tabular}

normal probability map of the residual, each point is substantially in a straight line. This indicates that the experimental data are in a normal distribution and no abnormal data points are present. In the residuals and operation sequence diagram, each point is scattered and has no special distribution. The results show that the experimental data are reasonable and the empirical model is significant.
3.2. Sensitivity Analysis. Sensitivity refers to the degree to which design objectives are sensitive to process parameters. The value of sensitivity can determine that the polishing process parameters are recognized as significant or insignificant, which is useful for accurately controlling the polishing process parameters [20]. If the objective function $f(x)$ is a derivable function, the sensitivity calculation 


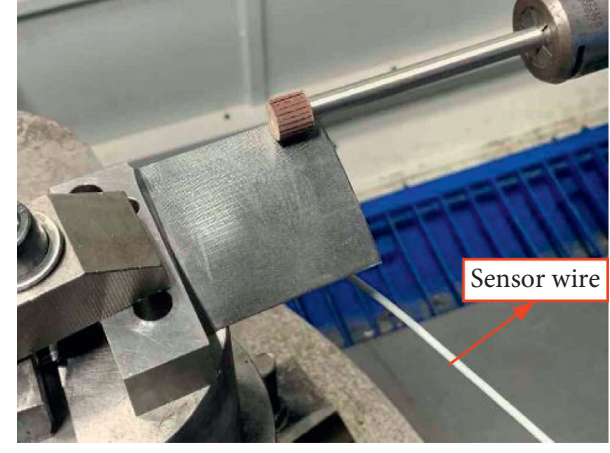

Figure 6: Polishing test site.

TABLE 5: Linear regression coefficient.

\begin{tabular}{lcccc}
\hline$c_{0}$ & $c_{1}$ & $c_{2}$ & $c_{3}$ & $c_{4}$ \\
\hline $10^{-0.92}$ & 0.408 & 0.467 & 0.043 & -0.166 \\
\hline
\end{tabular}

formula of the objective function to the variable $x$ is expressed as follows:

$$
S\left(x_{i}\right)=\frac{\partial f(x)}{\partial x_{i}}
$$

The concept of the relative sensitivity of polished vibration RMS value to polished processing parameters was proposed. The relative sensitivity can fully reflect the sensitivity of polished vibration RMS to process parameters. The sensitivity only reflects the change degree of the effective value of polishing vibration to the same parameter in different parameter ranges, such as the granularity change range of $240 \#$ to $600 \#$ and the compression depth change range of $0.2 \mathrm{~mm}$ to $0.6 \mathrm{~mm}$. Therefore, to obtain the influence of various process parameters on the polishing vibration, the relative sensitivity needs to be studied. The relative sensitivity calculation formula is expressed as follows:

$$
S^{\prime}\left(x_{i}\right)=\left|\frac{\Delta f\left(x_{i}\right) / f\left(x_{i}\right)}{\Delta x_{i} / x_{i}}\right|=\left|\frac{\Delta f\left(x_{i}\right)}{\Delta x_{i}} \frac{x_{i}}{f\left(x_{i}\right)}\right|=\left|S\left(x_{i}\right) \frac{x_{i}}{f\left(x_{i}\right)}\right| .
$$

According to formula (7), the sensitivity model of polishing vibration RMS to polishing process parameters is shown in the following formula:

$$
\left.\begin{array}{l}
S_{\psi(x)}^{n}=0.408 \times 10^{-0.92} \bar{n}^{-0.592} \bar{a}_{p}^{0.467} \bar{v}_{f}^{0.043} \bar{p}^{-0.166} \\
S_{\psi(x)}^{a_{p}}=0.467 \times 10^{-0.92} \bar{n}^{0.408} \bar{a}_{p}^{-0.533} \bar{v}_{f}^{0.043} \bar{p}^{-0.166} \\
S_{\psi(x)}^{v_{f}}=0.043 \times 10^{-0.92} \bar{n}^{0.408} \bar{a}_{p}^{0.467} \bar{v}_{f}^{-0.957} \bar{p}^{-0.166} \\
S_{\psi(x)}^{p}=-0.166 \times 10^{-0.92} \bar{n}^{0.408} \bar{a}_{p}^{0.467} \bar{v}_{f}^{0.043} \bar{p}^{-1.166}
\end{array}\right\}
$$

The average values of spindle speed, compression depth, feed rate, and granularity are shown in the following formula:
TABLE 6: Variance analysis.

\begin{tabular}{lccccc}
\hline Source & DOF & Adj SS & Adj MS & $F$ & $P$ \\
\hline Regression & 4 & 9.32 & 2.13 & 110.97 & $<0.001$ \\
Error & 4 & 0.073 & 0.017 & & \\
Total & 8 & 9.393 & & & \\
\hline
\end{tabular}

$$
\left\{\begin{array}{l}
\bar{n}=6000 \mathrm{r} / \mathrm{min}, \\
\bar{a}_{p}=0.6 \mathrm{~mm}, \\
\bar{v}_{f}=0.4 \mathrm{~mm} / \mathrm{min}, \\
\bar{p}=320 \# .
\end{array}\right.
$$

Substituting formula (6) into formula (8) can obtain the relative sensitivity of each process parameter to the polishing RMS value. The formula is as follows:

$$
\left.\begin{array}{l}
S^{\prime}(n)=S_{\psi(x)}^{n} \frac{n}{f\left(n, \bar{a}_{p}, \bar{v}_{f}, \bar{p}\right)}=0.408 \\
S^{\prime}\left(a_{p}\right)=S_{\psi(x)}^{a_{p}} \frac{a_{p}}{f\left(\bar{n}, a_{p}, \bar{v}_{f}, \bar{p}\right)}=0.467 \\
S^{\prime}\left(v_{f}\right)=S_{\psi(x)}^{v_{f}^{v}} \frac{v_{f}}{f\left(\bar{n}, \bar{a}_{p}, v_{f}, \bar{p}\right)}=0.043 \\
S^{\prime}(p)=S_{\psi(x)}^{n} \frac{p}{f\left(\bar{n}, \bar{a}_{p}, \bar{v}_{f}, p\right)}=-0.166
\end{array}\right\} .
$$

As can be seen from equation (11), $\left|S^{\prime}\left(a_{p}\right)\right|=0.467>\left|S^{\prime}(n)\right|=$ $0.408>\left|S^{\prime}(p)\right|=0.166>\left|S^{\prime}\left(v_{f}\right)\right|=0.043$. In order to obtain the coupling effect of process parameters on the polishing vibration signal RMS, the response surface is established as shown in Figure 8. In Figures 8(a), 8(b), and 8(d), the RMS value of polishing vibration signal changes greatly with the change of spindle speed and compression depth, and the RMS value of polishing vibration signal changes less with the change of feed rate. In Figures 8(c), 8(e), and 8(f), the RMS value of polishing vibration signal changes little with the change of granularity. Combining the response surface graph and equation (11), the sensitivity of the RMS value of the polishing vibration signal to the processing parameters is in order compression, spindle speed, granularity, and feed rate.

The sensitivities of RMS values of polishing vibration obtained by substituting formula (10) into formula (9) to process parameters are shown in the following formula:

$$
\left.\begin{array}{c}
S_{\psi(x)}^{n}=0.0137 \bar{n}^{-0.592} \\
S_{\psi(x)}^{a_{p}}=0.6946 \bar{a}_{p}^{-0.533} \\
S_{\psi(x)}^{v_{f}}=0.0524 \bar{v}_{f}^{-0.957} \\
S_{\psi(x)}^{p}=0.1362 \bar{p}^{-1.166}
\end{array}\right\} .
$$




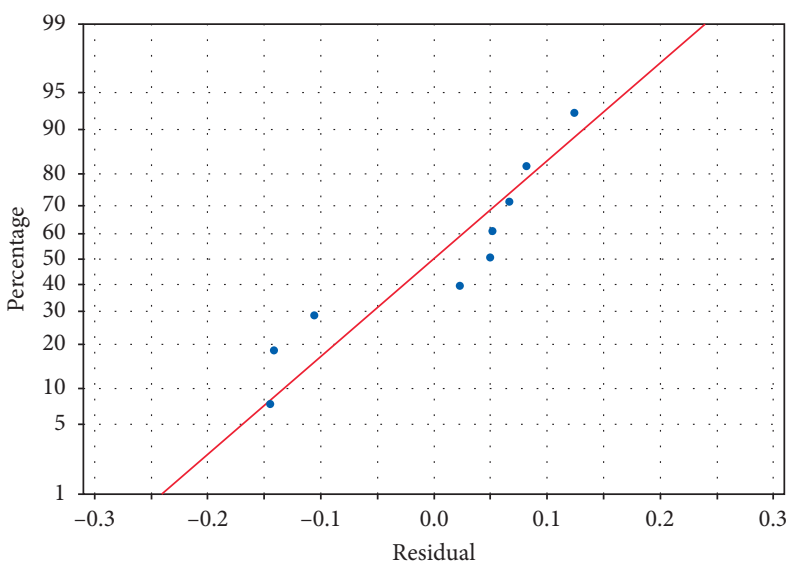

(a)

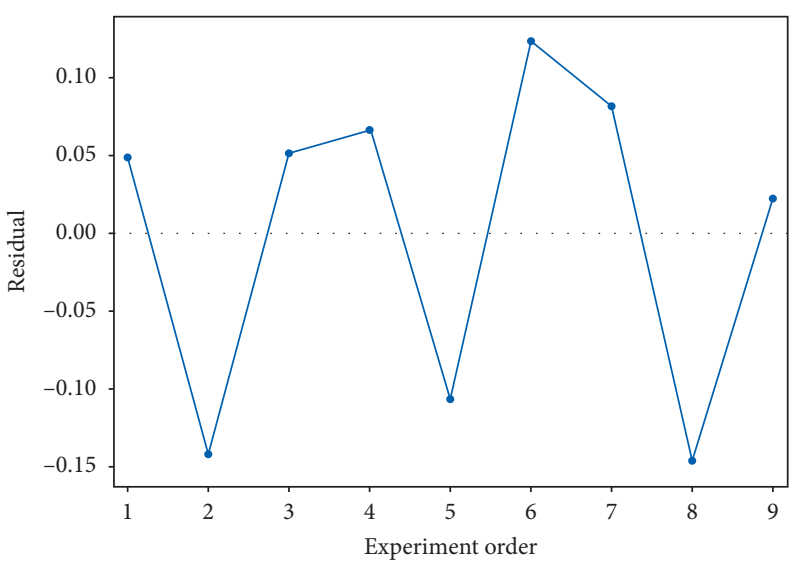

(b)

FIgURE 7: Normal probability of residuals and experimental order.

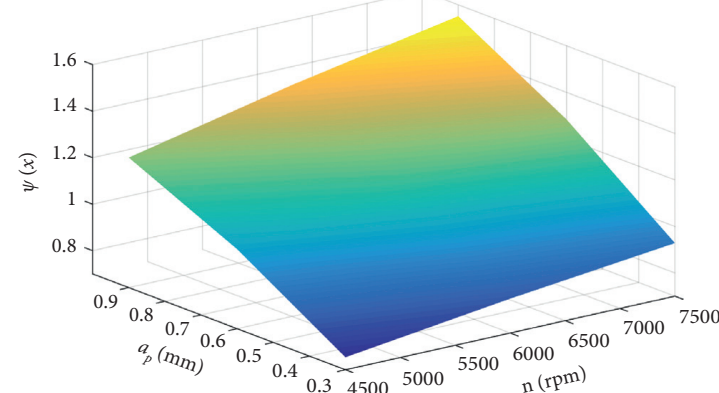

(a)

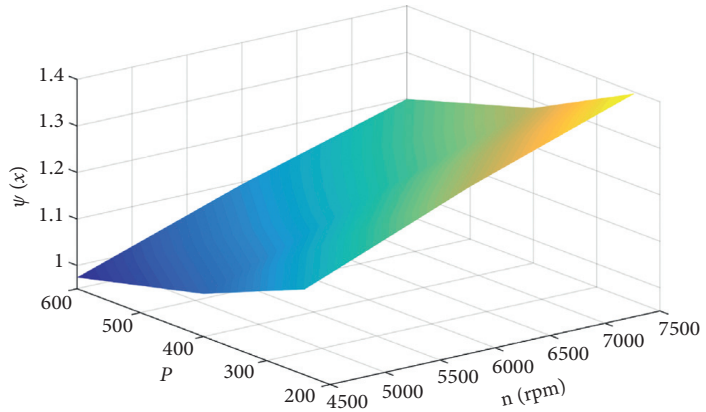

(c)

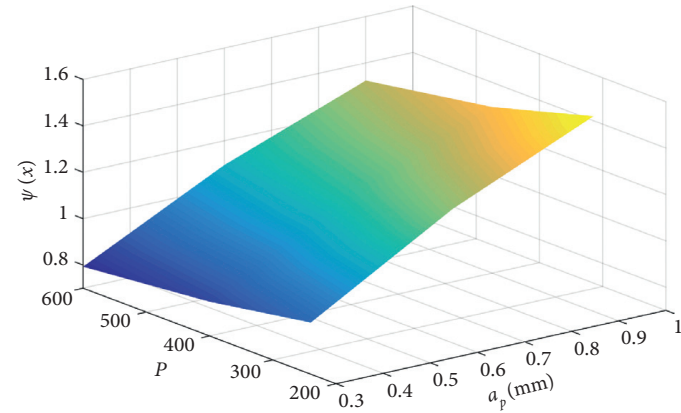

(e)

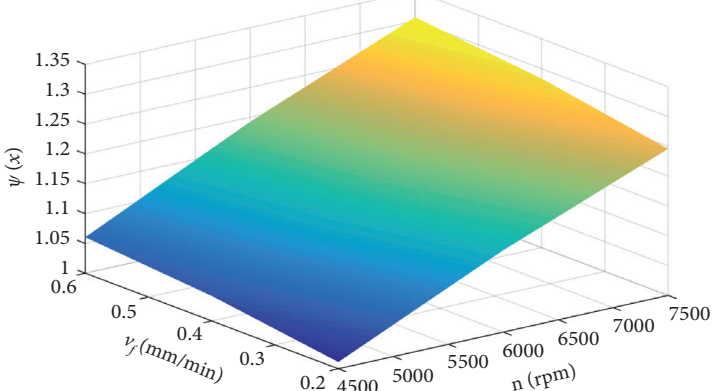

(b)

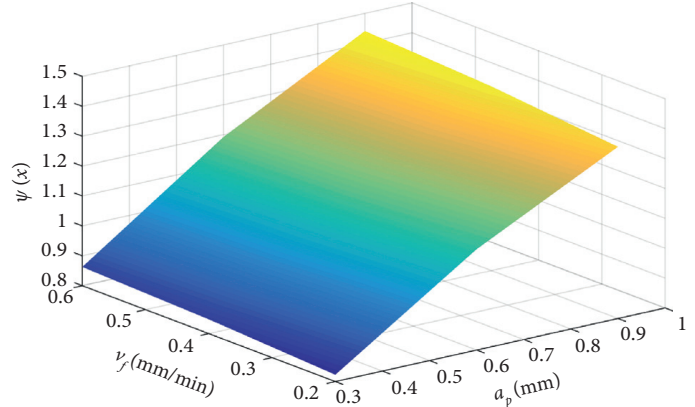

(d)



(f)

FIGURE 8: Response surface map. 


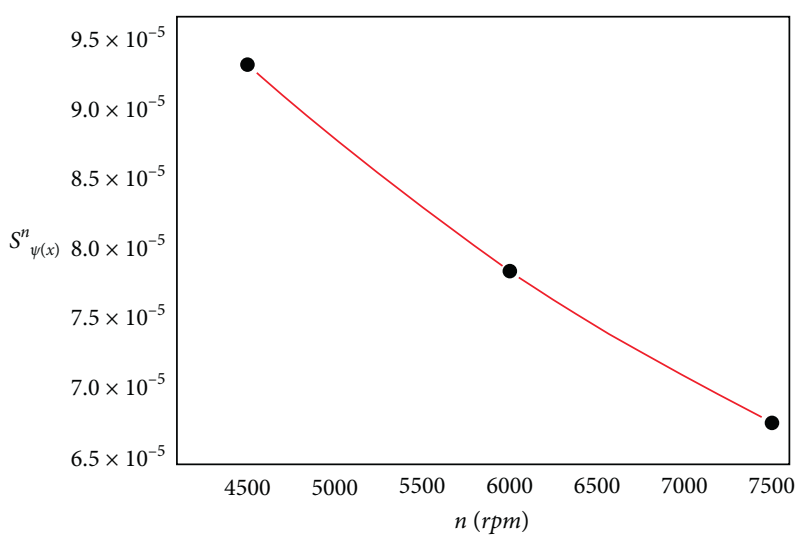

(a)

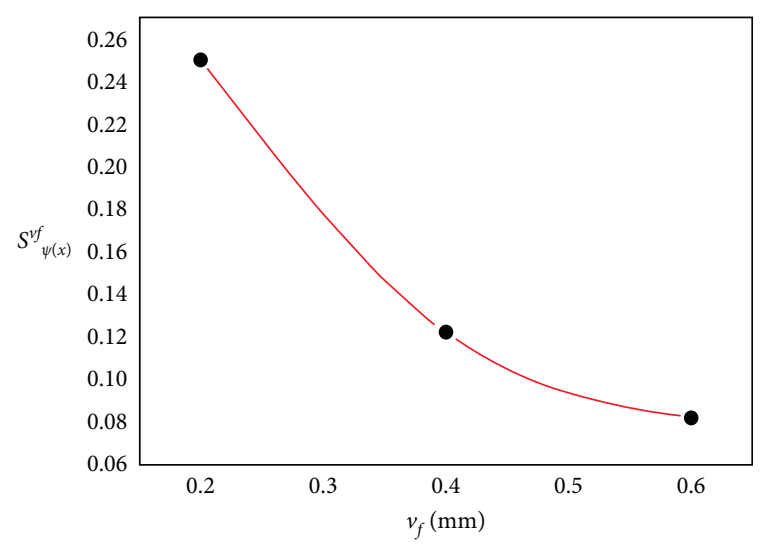

(c)

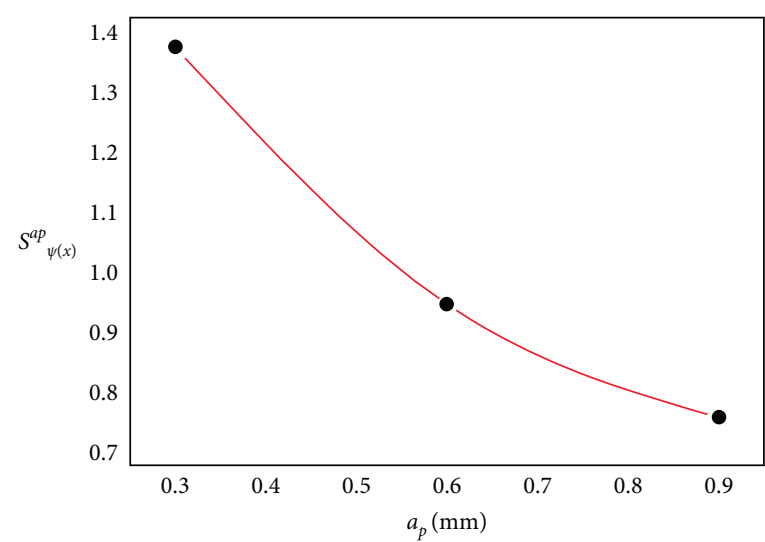

(b)

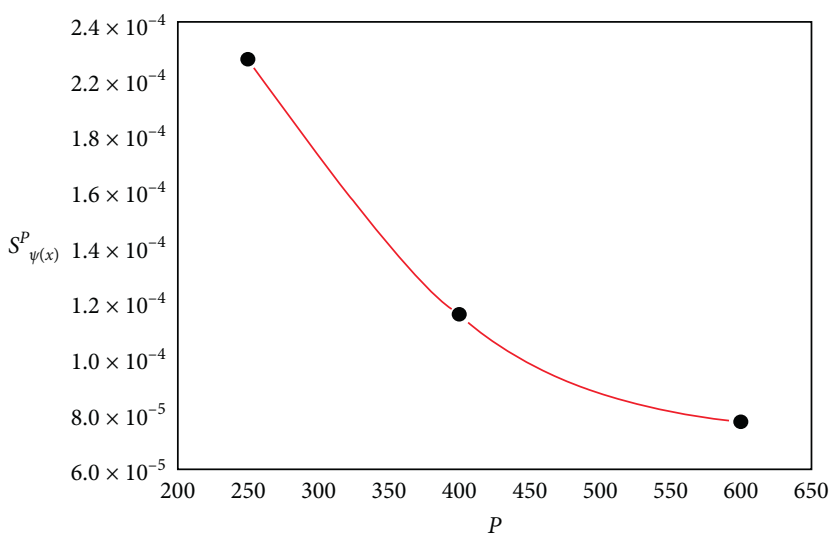

(d)

FIGURE 9: Sensitivity curves of polished vibration RMS value for processing parameters.

According to equation (12), the sensitivity curves of polishing vibration RMS value to spindle speed, compression depth, feed rate, and granularity were obtained, as shown in Figure 9. Based on the analysis of relative sensitivity, the feed rate is not further selected within the process parameter range. However, spindle speed, compression depth, and granularity need to be carefully selected within the process parameter range.

3.3. Determination of Stability Range of Process Parameters. In Figure 9(a), the sensitivity of polished vibration RMS value to spindle speed in the interval of [ $4500 \mathrm{r} / \mathrm{min}, 6000 \mathrm{r} / \mathrm{min}$ ] is higher than that in the interval of [6000 r/min, $7500 \mathrm{r} / \mathrm{min}$ ]. In Figure 9(b), the sensitivity of polished vibration RMS value to compression depth in the interval of $[0.3 \mathrm{~mm}, 0.6 \mathrm{~mm}]$ is higher than that in the interval of $[0.6 \mathrm{~mm}, 0.9 \mathrm{~mm}]$. In Figure $9(\mathrm{c})$, the sensitivity of polished vibration RMS value to feed rate in the interval of $[0.2 \mathrm{~mm} / \mathrm{min}, 0.4 \mathrm{~mm} / \mathrm{min}]$ is higher than that in the interval of $[0.4 \mathrm{~mm} / \mathrm{min}, 0.6 \mathrm{~mm} / \mathrm{min}]$.In Figure $9(\mathrm{~d})$, the sensitivity of polished vibration RMS value to granularity in the interval of [250\#, 400\#] is higher than that in the interval of [400\#, 600\#]. Therefore, the optimal stability ranges of significant parameters are compression depth within $[0.6 \mathrm{~mm}, 0.9 \mathrm{~mm}]$, spindle speed within
TABLE 7: Stable and unstable range of process parameters.

\begin{tabular}{lcc}
\hline Process parameters & Stable range & Unstable range \\
\hline$n(\mathrm{r} / \mathrm{min})$ & {$[6000,7500]$} & {$[4500,6000]$} \\
$a_{p}(\mathrm{~mm})$ & {$[0.6,0.9]$} & {$[0.3,0.6]$} \\
$v_{f}(\mathrm{~mm} / \mathrm{min})$ & {$[0.4,0.6]$} & {$[0.2,0.4]$} \\
$P$ & {$[400 \#, 600 \#]$} & {$[240 \#, 400 \#]$} \\
\hline
\end{tabular}

[6000 r/min, $7500 \mathrm{r} / \mathrm{min}]$, feed rate within $[0.4 \mathrm{~mm} / \mathrm{min}$, $0.6 \mathrm{~mm} / \mathrm{min}]$, and granularity within [400\#, 600\#].. The stable and unstable ranges of process parameters are shown in Table 7.

3.4. Experimental Verification. In order to verify the accuracy of the stable range, parameters in the stable and unstable ranges were selected for polishing experiments. The vibration RMS value and blade surface roughness were determined by experiments to determine whether the polishing process is stable and whether the polishing meets the requirements of blade profile accuracy.

The experiment was carried out on TC4 blisk, as shown in Figure 10. After the polishing test, the experimental results are shown in Table 8 . Measurement of blade surface 


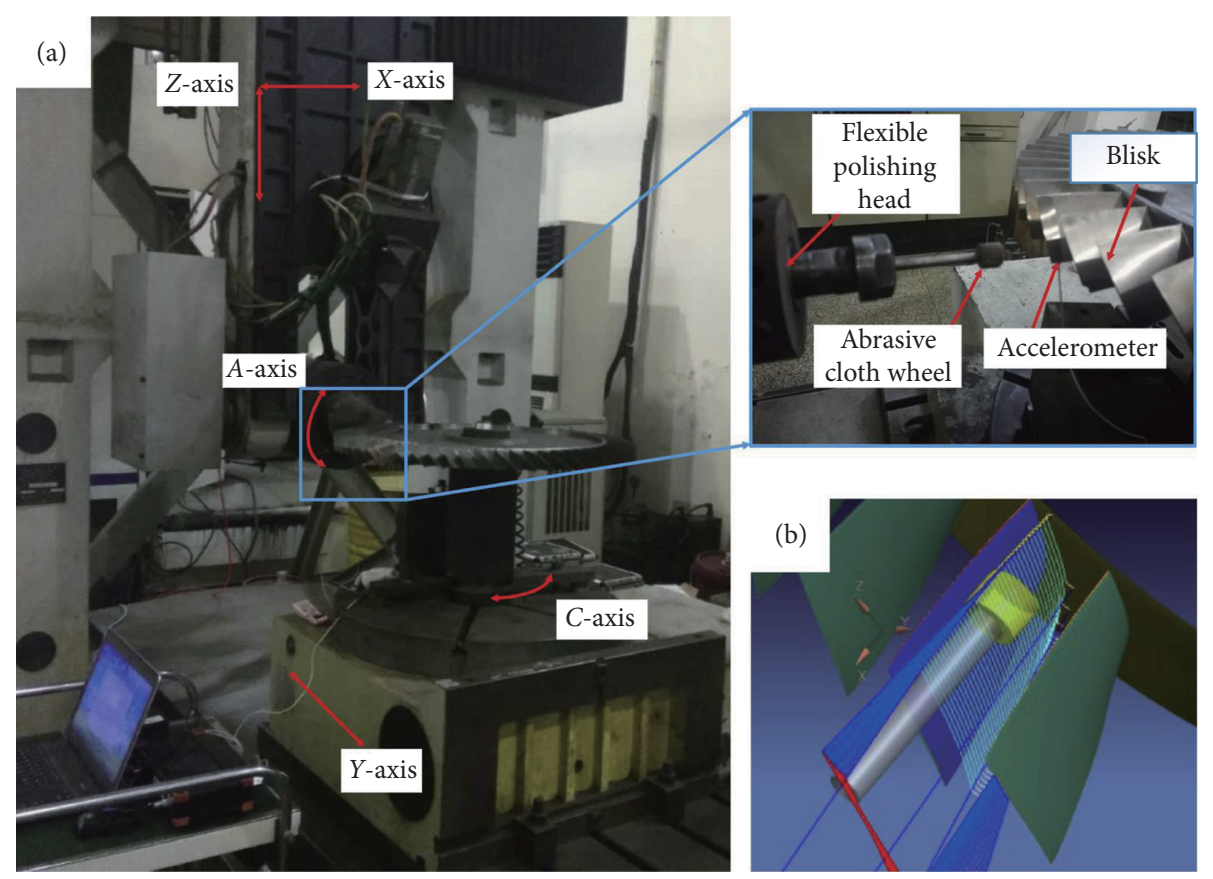

Figure 10: Polishing experiment verification.

TABLE 8: Experimental result.

\begin{tabular}{|c|c|c|c|c|c|c|}
\hline Number & $\begin{array}{c}\text { Spindle speed } \\
n\left(\mathrm{r} \cdot \mathrm{min}^{-1}\right)\end{array}$ & $\begin{array}{c}\text { Compression depth } \\
a_{p}(\mathrm{~mm})\end{array}$ & $\begin{array}{c}\text { Feed rate } \\
v_{f}\left(\mathrm{~m} \cdot \mathrm{min}^{-1}\right)\end{array}$ & $\begin{array}{c}\text { Granularity } \\
P\end{array}$ & $\begin{array}{c}\text { RMS value } \\
\psi(x)\left(\mathrm{m} \cdot \mathrm{s}^{-2}\right)\end{array}$ & $\begin{array}{c}\text { Roughness } \\
(\mu \mathrm{m})\end{array}$ \\
\hline 1 & 4500 & 0.3 & 0.2 & 200 & 1.06 & 0.358 \\
\hline 2 & 4500 & 0.6 & 0.4 & 400 & 1.01 & 0.31 \\
\hline 3 & 4500 & 0.9 & 0.6 & 600 & 1.05 & 0.32 \\
\hline 4 & 6000 & 0.3 & 0.4 & 600 & 1.25 & 0.383 \\
\hline 5 & 6000 & 0.6 & 0.6 & 200 & 1.18 & 0.37 \\
\hline 6 & 6000 & 0.9 & 0.2 & 400 & 1.29 & 0.22 \\
\hline 7 & 7500 & 0.3 & 0.6 & 400 & 1.20 & 0.27 \\
\hline 8 & 7500 & 0.6 & 0.2 & 600 & 1.28 & 0.25 \\
\hline 9 & 7500 & 0.9 & 0.4 & 200 & 1.34 & 0.234 \\
\hline
\end{tabular}

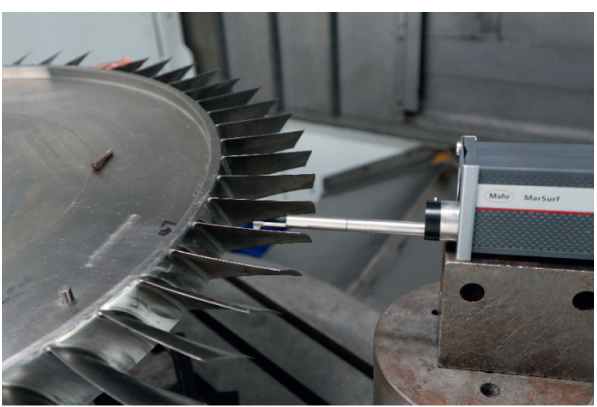

FIGURE 11: Measurement of blade surface roughness.

roughness by using the roughness measuring instrument is shown in Figure 11. The arithmetic average of the RMS of polishing vibration at each test level is calculated as the RMS of final polishing vibration.
3.5. Result Analysis. The variation curve of polishing vibration RMS value is shown in Figure 12. In Figure 12, the RMS value of theoretical polishing vibration is compared with that of actual polishing vibration. It is found that the trend of the two curves is the same, and the difference is small, which verifies the accuracy of the RMS value model of polishing vibration. According to Figure 12(a), the RMS value of polishing vibration in the stable range of spindle speed is $1.2 \mathrm{~m} / \mathrm{s}^{2}$ to $1.22 \mathrm{~m} / \mathrm{s}^{2}$. It can be seen from Figure 12(b) that the RMS value of polishing vibration in the stable range of the compression depth is $1.02 \mathrm{~m} / \mathrm{s}^{2}$ to $1.47 \mathrm{~m} / \mathrm{s}^{2}$. It can be seen from Figure 12(c) that the RMS value of polishing vibration in the stable range of feed rate is $1.15 \mathrm{~m} / \mathrm{s}^{2}$ to $1.19 \mathrm{~m} / \mathrm{s}^{2}$. It can be seen from Figure $12(\mathrm{~d})$ that the RMS value of polishing vibration in the stable range of granularity is $1.05 \mathrm{~m} / \mathrm{s}^{2}$ to $1.22 \mathrm{~m} / \mathrm{s}^{2}$. Parameter interval optimization is shown in Table 9.

It can be seen from Table 9 that the RMS value of the polishing vibration signal in the stable range is less than 


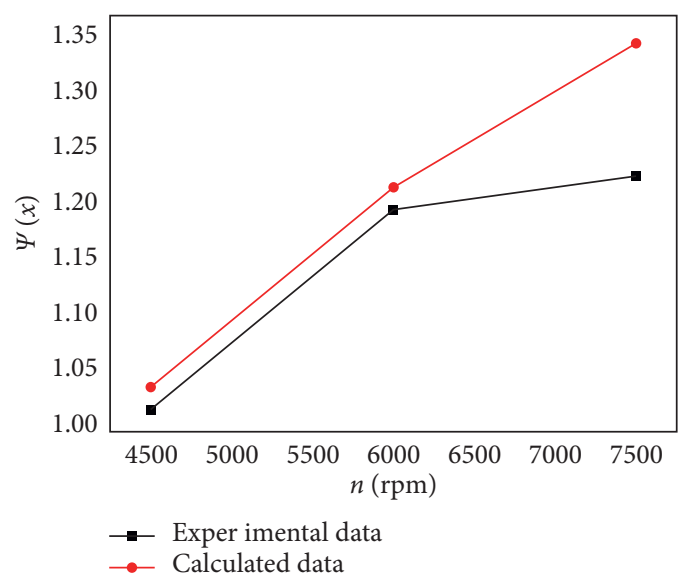

(a)

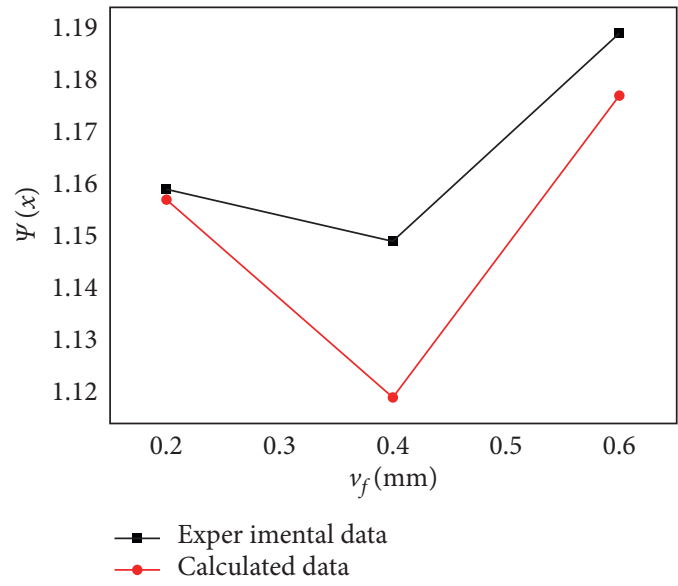

(c)

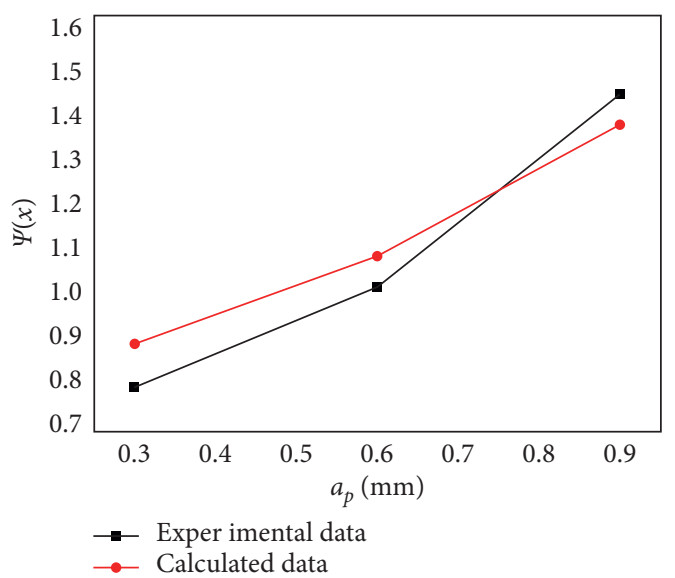

(b)

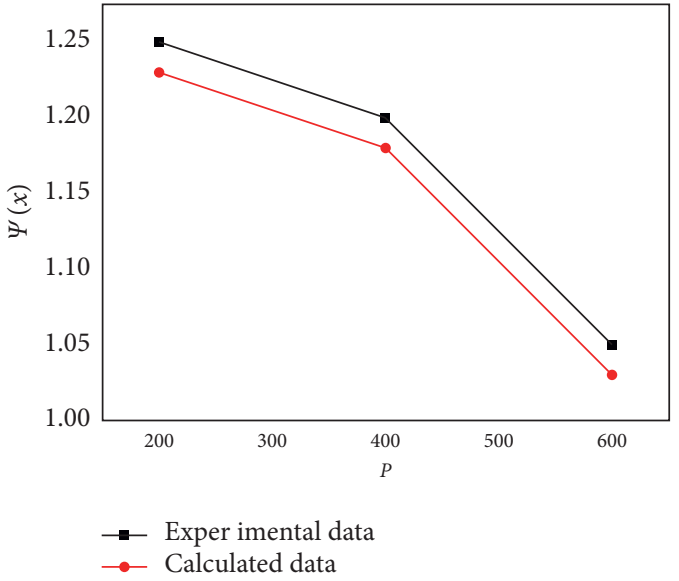

(d)

FIGURE 12: Influencing curves of polishing process parameters on polished vibration RMS value.

Table 9: Parameter interval optimization.

\begin{tabular}{lccc}
\hline Process parameters & Interval optimization & Stability & Polishing vibration RMS value \\
\hline$n(\mathrm{r} / \mathrm{min})$ & {$[6000,7500]$} & Stable & $<1.5$ \\
$a_{p}(\mathrm{~mm})$ & {$[0.6,0.9]$} & Stable & $<1.5$ \\
$v_{f}(\mathrm{~mm} / \mathrm{min})$ & {$[0.4,0.6]$} & Stable & $<1.5$ \\
$P$ & {$[400 \#, 600 \#]$} & Stable & $<1.5$ \\
\hline
\end{tabular}

$1.5 \mathrm{~m} / \mathrm{s}^{2}$, which is very small compared to the milling vibration and does not destabilize the polishing process [21].

Analysis of the size of the polishing vibration signal alone does not determine the stability of the polishing process. It is also necessary to study the characteristics of the vibration signal. In order to obtain the characteristics of the polishing vibration signal, the FFT spectrum analysis of the polishing signal must be performed, and the analysis result is shown in Figure 13.

Figure 13(a) shows the spectrum of the vibration signal. From the spectrum, it can be seen that the main spectrums of vibration during the polishing of thin-walled leaves are $879 \mathrm{~Hz}$ and $1997 \mathrm{~Hz}$. Compared with milling, the vibration signal during polishing is high-frequency vibration, and the frequency spectrum characteristic of polishing is single. As shown in Figure 13(b), the time-domain signal during polishing is stable without fluctuations.

According to the analysis of the polishing vibration signal RMS value and the characteristics of the polishing vibration signal, it is proved that the polishing process is stable within the stable range. The stability range is effective.

Although the polishing process is stable, it is also necessary to analyze the surface quality of the blade to verify whether the blade profile accuracy meets the requirements. The surface of the blade of the first group was observed, and the surface texture of the blade is shown in Figure 14. In Figure 14(a), obvious milling marks were found. It can be seen in Figure 14(b) that the milling traces are removed by polishing. The three-dimensional surface topography of the blade is shown in Figure 15. A significant difference in the 


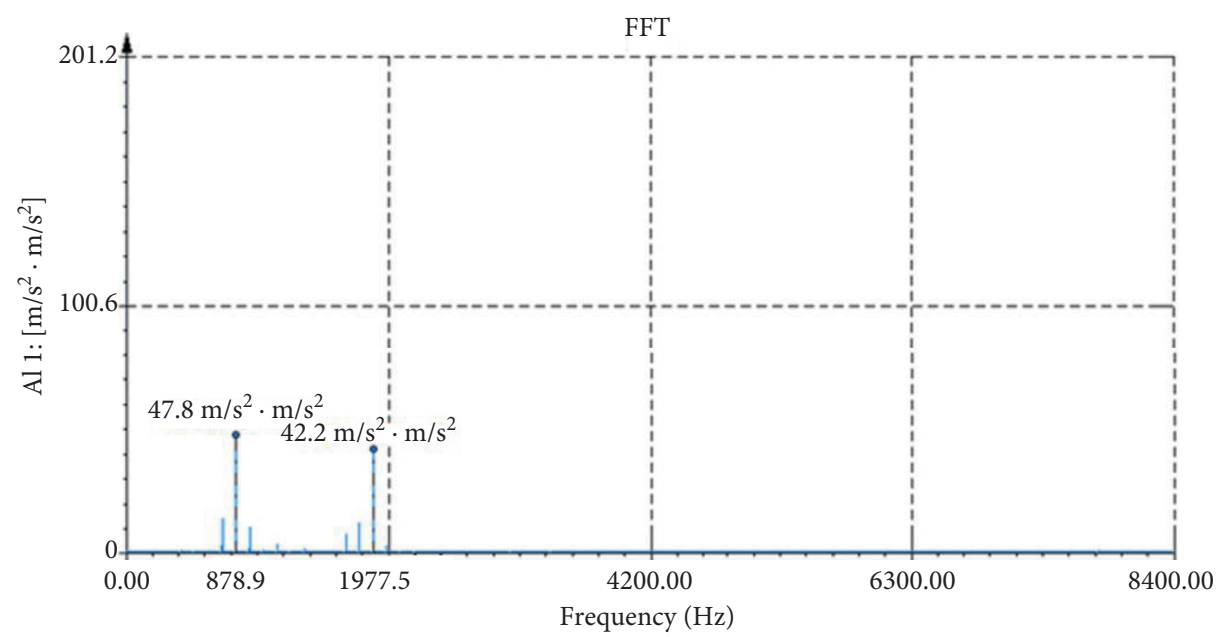

(a)

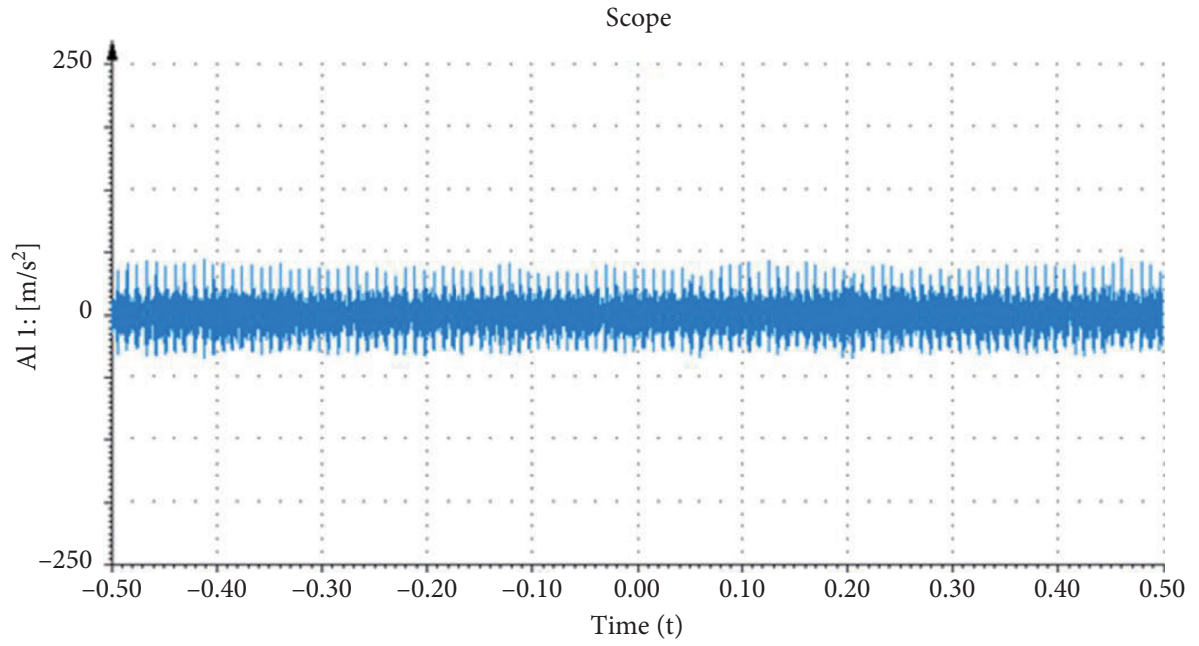

(b)

FIGURE 13: Spectrum of polishing vibration signal at $6000 \mathrm{r} / \mathrm{min}$.

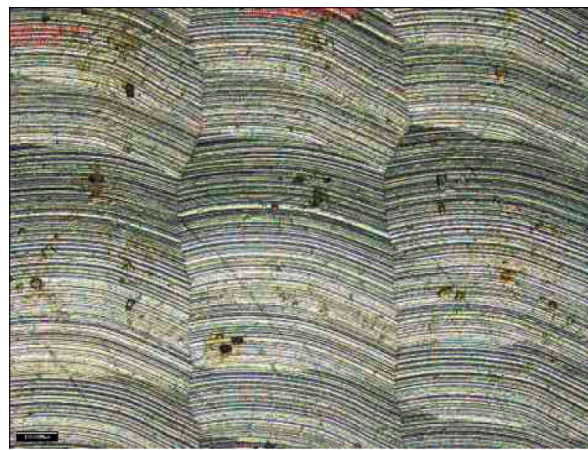

(a)

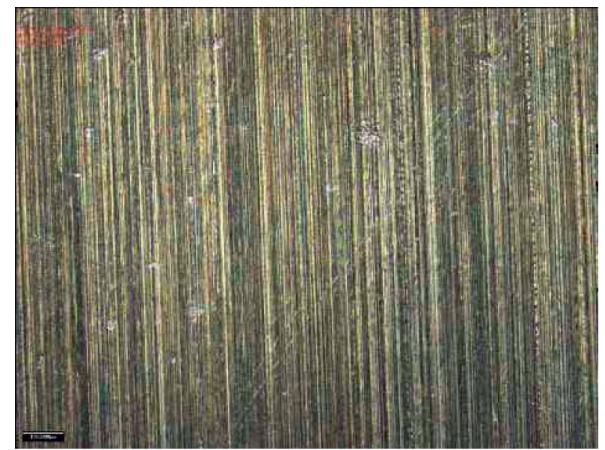

(b)

FIGURe 14: Changes of blade surface texture before and after polishing. (a) Surface texture before polishing. (b) Surface texture after polishing.

height of the blade surface can be seen from Figure 15(a). It can be seen from Figure 15(b) that the blade surface height remains the same. Figure 16(a) shows that the surface roughness of the blade surface after milling is large.
Figure 16(b) shows that the peaks and troughs of the roughness are reduced.

In conclusion, by analyzing the characteristics of blade surface morphology and polishing vibration signal, it is 


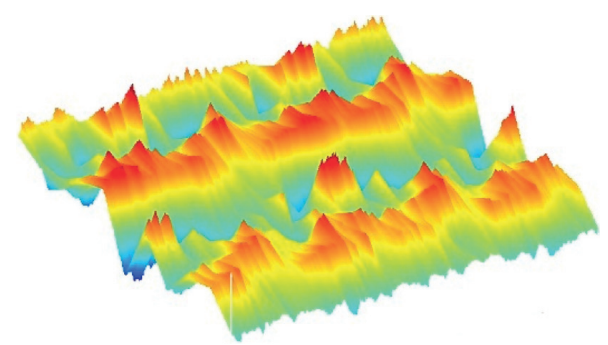

(a)

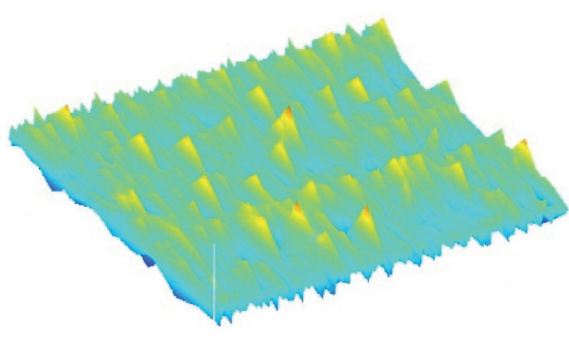

(b)

FIGURE 15: Changes of blade surface texture before and after polishing. (a) Blade surface morphology before polishing. (b) Blade surface morphology after polishing.

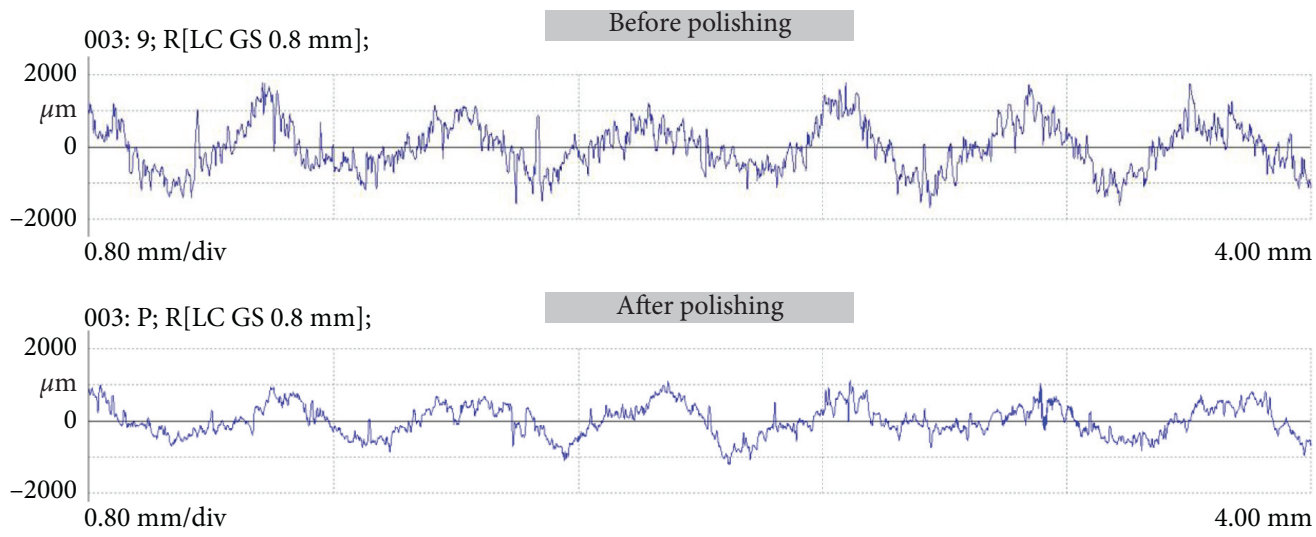

FIGURE 16: Roughness curve.

found that the polishing process is stable without large vibration in the stable range, and the polished blade meets the requirements of profile accuracy.

\section{Conclusion}

In this paper, the empirical model between the RMS value of the polishing vibration signal and the process parameters is obtained by the orthogonal experimental regression modeling method. The sensitivity analysis of the empirical model is carried out to obtain the stable range of the process parameters. The analysis results are as follows:

(1) An orthogonal test scheme was established by the polishing test, and the experimental data were subjected to regression analysis to obtain the empirical model of the RMS value of polishing vibration. The relative sensitivity analysis of the model shows that the order of influence of each process parameter on the RMS value of polishing vibration was as follows: compression depth, spindle speed, granularity, and feed rate.

(2) Through sensitivity analysis, the optimal stability ranges are recognized: compression depth within [0.6 $\mathrm{mm}, 0.9 \mathrm{~mm}]$, spindle speed within $[6000 \mathrm{r} / \mathrm{min}$, $7500 \mathrm{r} / \mathrm{min}]$, feed rate within $[0.4 \mathrm{~mm} / \mathrm{min}$, $0.6 \mathrm{~mm} / \mathrm{min}$ ], and granularity within [400\#, 600\#]. It was verified by experiments that the RMS values of polished vibration signals in the stable range were all less than $1.5 \mathrm{~m} / \mathrm{s}^{2}$, with single signal characteristics and no fluctuation.

(3) The RMS value of polishing vibration can be calculated by using the polishing vibration model, which can judge whether the polishing process is stable and whether the process parameters are reasonable.

(4) Selecting the process parameters in the stable range for polishing experiments will not produce large vibrations and will not destabilize the polishing process. The polished blades meet the requirements of profile accuracy.

\section{Data Availability}

The data used to support the findings of this study are included within the article.

\section{Conflicts of Interest}

The authors declare that they have no conflicts of interest.

\section{Acknowledgments}

This research was supported by the National Natural Science Foundation of China (no. 51675439). 


\section{References}

[1] P. B. Zhao, Y. Y. Shi, and L. I. Xiao-Biao, "Compensation control of belt polishing force for aero-engine blade based on disturbance observer," Computer Integrated Manufacturing Systems, vol. 19, no. 6, pp. 1279-1287, 2013.

[2] G. Xiao and H. Yun, "Constant-load adaptive belt polishing of the weak-rigidity blisk blade," International Journal of Advanced Manufacturing Technology, vol. 78, no. 9-12, pp. 1473-1484, 2015.

[3] D. A. Axinte, M. Kritmanorot, M. Axinte, and N. N. Z. Gindy, "Investigations on belt polishing of heat-resistant titanium alloys," Journal of Materials Processing Technology, vol. 166, no. 3, pp. 398-404, 2005.

[4] D. A. Axinte, J. Kwong, and M. C. Kong, "Workpiece surface integrity of Ti-6-4 heat-resistant alloy when employing different polishing methods," Journal of Materials Processing Technology, vol. 209, no. 4, pp. 1843-1852, 2009.

[5] A. Jourani, M. Dursapt, H. Hamdi, J. Rech, and H. Zahouani, "Effect of the belt grinding on the surface texture: modeling of the contact and abrasive wear," Wear, vol. 259, no. 7-12, pp. 1137-1143, 2005.

[6] M. Bigerelle, A. Gautier, B. Hagege, J. Favergeon, and B. Bounichane, "Roughness characteristic length scales of belt finished surface," Journal of Materials Processing Technology, vol. 209, no. 20, pp. 6103-6116, 2009.

[7] M. Bigerelle, D. Najjar, and A. Iost, "Multiscale functional analysis of wear," Wear, vol. 258, no. 1-4, pp. 232-239, 2005.

[8] Z. Huang, Y. Huang, Y. Y. Wu, and W. W. Zhang, "Finishing advanced surface of magnesium alloy tube based on abrasive belt grinding techology," Materials Science Forum, vol. 610-613, pp. 975-978, 2009.

[9] F. Tian, C. Lv, Z. Li, and G. Liu, "Modeling and control of robotic automatic polishing for curved surfaces," CIRP Journal of Manufacturing Science and Technology, vol. 14, pp. 55-64, 2016.

[10] L. Pilný and G. Bissacco, "Development of on the machine process monitoring and control strategy in Robot Assisted Polishing," CIRP Annals, vol. 64, no. 1, pp. 313-316, 2015.

[11] Y. Sun, D. J. Giblin, and K. Kazerounian, "Accurate robotic belt grinding of workpieces with complex geometries using relative calibration techniques," Robotics and Computer-Integrated Manufacturing, vol. 25, no. 1, pp. 204-210, 2009.

[12] S. Mirian, M. Safavi, A. Fadaei, M. Salimi, and M. Farzin, "Improving the quality of surface in polishing process with the magnetic abrasive powder polishing (MAPP) by use of ultrasonic oscillation of work-piece on a CNC table," International Journal of Precision Engineering and Manufacturing, vol. 12, no. 2, pp. 275-284, 2011.

[13] S. S. Mirian, A. Fadaei, S. M. Safavi et al., "Improving the quality of surface in the polishing process with the magnetic abrasive powder polishing using a high-frequency induction heating source on CNC table," International Journal of Advanced Manufacturing Technology, vol. 55, no. 5-8, pp. 601610, 2011.

[14] C. R. Dunn and D. D. Walker, "Pseudo-random tool paths for CNC sub-aperture polishing and other applications," Optics Express, vol. 16, no. 23, Article ID 18942, 2008.

[15] W. W. Zhang, G. Guo, Y. Zhang et al., "Tool path planning and geometry simulation for multi-axis CNC belt grinding," Journal of Chongqing University, vol. 33, no. 9, pp. 8-13, 2010.

[16] J. Duan, Y. Shi, J. Zhang et al., "Flexible polishing technology for blade of aviation engine," Acta Aeronautica Et Astronautica Sinica, vol. 33, no. 3, pp. 573-578, 2012.
[17] D. Wu, H. Wang, K. Zhang, and X. Lin, "Research on formation mechanism and optimization method of surface waviness of TC4 blisk blade," Journal of Manufacturing Processes, vol. 39, pp. 305-326, 2019.

[18] H. Wenbo, H. Tang, Y. Shi et al., "Modelling and parameter optimization of flexible polishing force for abrasive cloth wheel," Acta Aeronautica Et Astronautica Sinica, vol. 37, no. 11, 2016.

[19] H. Wenbo, Y. Shi, H. Tang et al., "Experimental analysis and modeling for CNC polishing force of abrasive cloth flap wheel," Computer Integrated Manufacturing Systems, vol. 23, no. 2, pp. 315-324, 2017.

[20] H. Wenbo and H. Tang, "Interval optimization of polishing process parameters for abrasive cloth wheel facing surface roughness," Aviation Precision Manufacturing Technology, vol. 53, no. 2, pp. 14-18, 2017.

[21] Nanjing University of Aeronautics and Astronautics, Vibration Monitoring and Analysis of Milling Process, Nanjing University of Aeronautics and Astronautics, Nanjing, China, 2009. 